\title{
Empirical Correlation between Hub Height and Local Wind Shear Exponent for Different Sizes of Wind Turbines
}

\author{
Shafiqur Rehman ${ }^{1,2, *}$, Luai M. Al-Hadhrami ${ }^{1}$, Md. Mahbub Alam²,3 ${ }^{2}$ J. P. Meyer ${ }^{2}$ \\ ${ }^{1}$ Center for Engineering Research, Research Institute, King Fahd University of Petroleum and Minerals, Dhahran- \\ 31261, Saudi Arabia \\ Telephone: +96638603802 Mobile: +966 502085496 \\ E-mail: srehman@kfupm.edu.sa \\ ${ }^{1}$ Center for Engineering Research, Research Institute, King Fahd University of Petroleum and Minerals, Dhahran- \\ 31261, Saudi Arabia \\ Telephone: +966 $38602888 \quad$ Fax: +966 38603996 \\ E-mail: luaimalh@kfupm.edu.sa \\ ${ }^{2}$ Mechanical and Aeronautical Engineering Department, University of Pretoria, Pretoria, South Africa \\ E-mail: Josua.Meyer@up.ac.za \\ ${ }^{3}$ Shenzhen Graduate School, Harbin Institute of Technology, University Town, Xili, Shenzhen 518055, P. R China \\ E-mail: alamm28@yahoo.com
}

\begin{abstract}
Alarmingly increasing rates of adverse environmental happenings have lead the people from all walks of life towards utilization of clean and renewable sources of energy. Due to technological advancement and availability of efficient wind turbines of few tens of kilowatts to multi-megawatt seizes which covers all human applications have made the utilization of wind power as the technology of choice. For its optimal utilization, site dependent analysis of the wind and its variation with height and then economics of increasing the tower height (hub height) have become necessary factors. This paper proposes a new correlation for the estimation of optimal hub height for harnessing the power of the wind on economically competitive basis. For this purpose, seven empirical correlations have been developed for seven sites for wind turbines of rated power of 600 to $5000 \mathrm{~kW}$. Wind speed measurements made at 20,30, and 40 meters at seven sites have been used in the present work.
\end{abstract}

Keywords: Wind speed, wind power, hub height, wind shear exponent, wind turbine

\footnotetext{
* Corresponding author: Shafiqur Rehman, KFUPM Box 767, Dhahran-31261, Saudi Arabia; E-mail: srehman@kfupm.edu.sa; Telephone: +966 38603802 Fax: +966 38603996
} 


\section{Introduction}

In this highly competitive, extremely materialistic and up-to-date know how scenario, smart and optimal utilization of sources of energy has become essential. Exponentially increasing global and regional population, widening of gap between the production and demands of essential commodities, environmental pollution levels, and resulting adverse climatic changes, have become the matters of concern to individuals, engineers, environmentalists, and even politicians in the recent years. To conserve fossil fuel and combat the adverse effects of changing climatic conditions on the environment, clean and renewable sources of energy are being developed and utilized on global, regional, and local scales both onshore and offshore. Still, there are more than 2 billion people who have not experienced the delight of grid connected electricity both in developed and developing countries [1]. Due to fast wind power generation technology development, commercial acceptability, robust design, ease of operation and maintenance, and economic compatibility with traditional sources of energy; power of the wind is being utilized globally for both grid connected utility scale and small isolated grid applications. It is very important and critical to conduct wind resources assessment of the site of interest because the energy output is highly dependent on the wind conditions of the geographical location [2-4].

Wind power is a clean, economical, and intermittently available source of energy. Today's modern wind turbines can be installed quickly and easily. It is the leading electricity generation technology in the fight against climate change, enhancing energy security, stabilizing electricity prices, cleaning up air and creating thousands of jobs in the manufacturing sector. Global Wind Energy Council's (GWEC's) prediction of 12\% growth in the wind sector was generally greeted with disbelief and derision but the global market grew by $41 \%$ in 2009 , demonstrating that wind power is increasingly the power technology of choice. The annual cumulative wind power installed capacity reached $237.669 \mathrm{GW}$ in 2011 compared to $197.637 \mathrm{GW}$ in 2010 and $158.5 \mathrm{GW}$ in 2009 , an increase of $20.62 \%$ and $24.69 \%$, respectively, GWEC [5]. This represents a year-onyear growth of $31.7 \%$. One third of these additions were made in China, which doubled its installed capacity yet again. Since 2005, the global wind power growth has been always been more than 25\%. For the second consecutive year, Asia remained the world's largest regional market for wind energy, with capacity additions amounting to $20.929 \mathrm{GW}$ and $15.4 \mathrm{GW}$ in 2011 and 2010, respectively. 
Wind speed increases with height which means more power at higher hub heights [6]. Furthermore, hub height optimization is a key towards profitable wind power projects. Hub height is defined as the distance between the platform and the rotor of the wind turbine [7], as shown in Fig. 1. The additional cost for higher hub heights differs greatly from one manufacture to another [8]. According to Hoffmann et al. [8], the profitability can be enhanced from $2.1 \%$ to $37.6 \%$ by choosing the optimal available hub height rather than standard hub height provided by the manufacturer. The height of the hub of a wind turbine can determine success or failure of the wind power project. There are two primary factors to be considered when determining how high a tower need to be to enable a wind turbine to be effective and efficient [9]. The first factor is that the wind speed increases with height. Hence a wind turbine will be able to extract more power from the wind if it is installed on a higher tower. The second consideration when determining the hub height is the minimization or avoidance of the turbulence. Turbulence decreases the effectiveness of the turbine resulting in decreased electricity generation and tends to increase the wear and tear on the turbine resulting in increased maintenance and decreased operational life.

Wind is a naturally occurring phenomenon and is beyond human's manipulation, but there is one thing that can be done to increase the wind speed experienced by a wind turbine at a given location; go upwards by increasing the tower height [10]. As mentioned in reference [10], as wind gets closer to the ground it loses some of its speed due to friction as it rubs against any 'surface roughness'. For each 1 meter increase in the hub-height of a farm wind turbine the annual energy production increases by 1\%, [10]. According to Firtin et al. [11], a difference of up to $49 \%$ in energy yield may be obtained if using extrapolated wind data based on constant values of wind shear exponent and energy production using measured wind data at hub height. Therefore it is preferable financially to opt for the highest tower available for wind turbine installation. In modern times, wind turbines have been made larger and softer to increase profitability. Due to this technological advancement in wind turbines sizes, tower optimization becomes more important, as towers account for 20-30\% of turbine cost Yoshida [12]. Yoshida [12] developed a wind turbine tower optimization program using a genetic algorithm which allowed a rational analysis to reduce the mass of turbine towers by considering the distributions of its diameter and wall thickness, and the positions of flanges and access ports to navigation lights. 
The present work utilized wind speed measurements made at 20,30, and 40 meters above ground level at Arar, Dhahran, Dhulom, Gassim, Juaymah, Rawdat Ben Habbas (RBH) and Yanbo stations in Saudi Arabia in conjunction with wind turbines of rated power of 600, 1000, $2000,3000,3600$, and $5000 \mathrm{~kW}$ for the development of empirical correlations to determine the optimal height as a function of local wind shear exponent. The local wind shear exponent is determined using wind measurements at different heights at these sites as reported in [13-19]. The next section provides the procedure adopted over reaching the proposed empirical correlations.

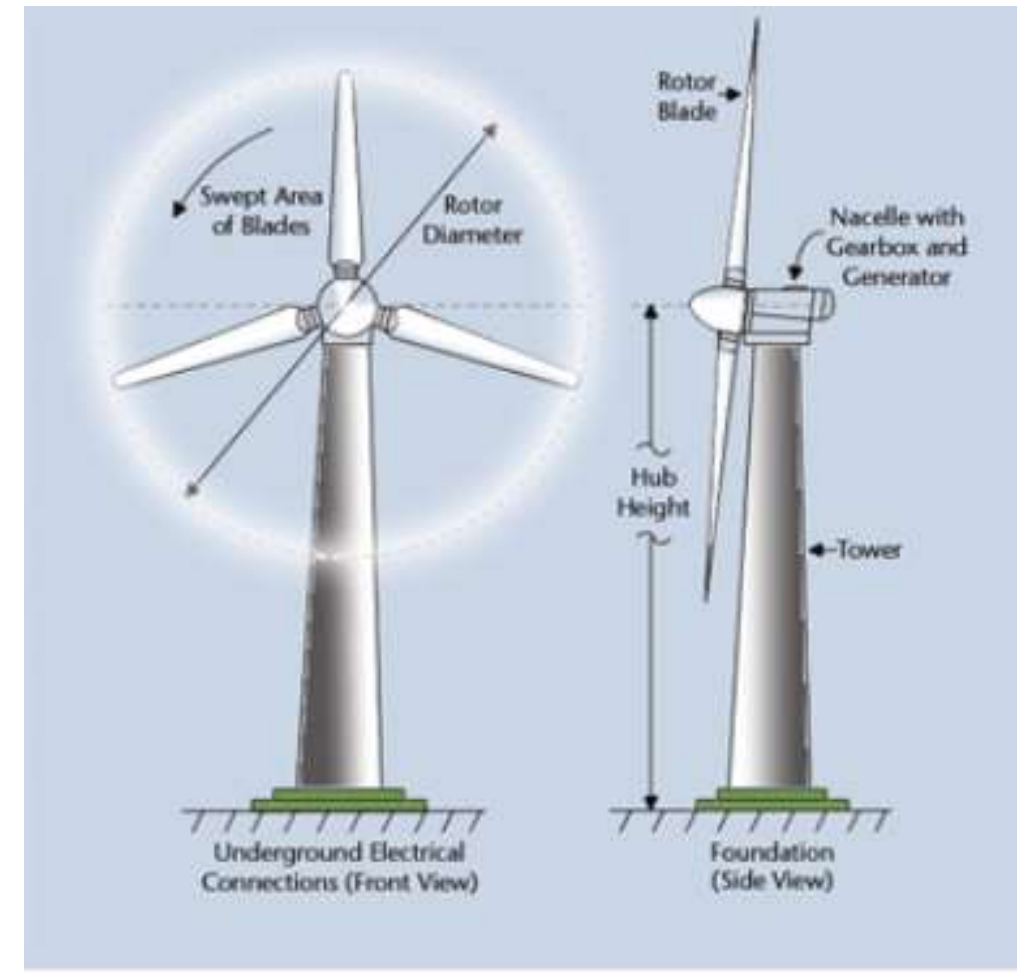

Fig. 1. Pictorial representation of wind turbine hub height [7]

\section{Procedure for Empirical Model Development}

An attempt has been made to develop an empirical model for the estimation of near optimal hub height based on local wind shear exponent. To the best of author's knowledge, this will be the first attempt towards development of an empirical model for the estimation of optimal hub height. Following steps are followed to the set objective: 
1. Annual energy yield is estimation for a chosen wind turbine of certain rated power (600, $1000,2000,3000,3600$, and $5000 \mathrm{~kW}$ in the present case) at different hub heights $(40,50,60$, $70,80,90,100,110,120 \mathrm{~m}$ in the present case)

2. Estimation of percent increase in annual energy yield for each $10 \mathrm{~m}$ increases in hub height

3. Cost of chosen wind turbine (capital + installation + operation + maintenance)

4. Estimation or assumption of percent incremental total cost for each $10 \mathrm{~m}$ increase in hub height

5. Plotting of percent incremental change in annual energy yield and the corresponding percent costs against hub height increase

6. The point where the two curves cross each other is taken as the optimal or near optimal hub height

The point at which the two curves cross each other, the percent rate of increase in annual energy yield becomes very small and the rate of increase in percent total cost starts increasingly higher and higher.

\section{Data and Site Description}

The geographical details including the latitude, longitude and the altitude of all the stations are summarized in Table 1. The wind speed measurements were made at 20, 30 and 40 meters above ground level (AGL) and the wind direction sensors were installed at 30 and 40m AGL, as shown in Fig. 2. The meteorological sensors such temperature, relative humidity, pressure, and global solar radiation were installed at $1.5 \mathrm{~m}$ AGL. The technical specifications of all the sensors used in this study are summarized in Table 2. The values of local WSE are summarized in Table 3.

\section{Table 1}

Site specific information of data collection stations.

\begin{tabular}{lccrc}
\hline \multicolumn{1}{c}{ Location } & $\begin{array}{c}\text { Latitude } \\
\left({ }^{\circ}\right)\end{array}$ & $\begin{array}{c}\text { Longitude } \\
\left({ }^{\circ}\right)\end{array}$ & $\begin{array}{c}\text { Altitude } \\
(\mathrm{m})\end{array}$ & Period \\
\hline Rawdat Ben Habbas & $29.14^{\circ} \mathrm{N}$ & $44.33^{\circ} \mathrm{E}$ & 443 & Sep. 2005 to Apr. 2010 \\
Juaymah & $26.80^{\circ} \mathrm{N}$ & $49.90^{\circ} \mathrm{E}$ & 20 & Jul. 2006 to Apr. 2009 \\
Dhahran & $26.10^{\circ} \mathrm{N}$ & $50.10^{\circ} \mathrm{E}$ & 3 & Oct. 1995 to Nov. 2000 \\
Arar & $30.80^{\circ} \mathrm{N}$ & $41.30^{\circ} \mathrm{E}$ & 550 & Jun. 1995 to Dec. 1998 \\
Gassim & $26.30^{\circ} \mathrm{N}$ & $43.97^{\circ} \mathrm{E}$ & 648 & Dec. 1995 to Oct. 1998 \\
Yanbo & $23.90^{\circ} \mathrm{N}$ & $38.30^{\circ} \mathrm{E}$ & 11 & Sep. 1996 to Oct. 1999 \\
Dhulom & $22.74^{\circ} \mathrm{N}$ & $42.18^{\circ} \mathrm{E}$ & 1117 & Nov. 1998 to Oct. 2002 \\
\hline
\end{tabular}




\section{Table 2}

Details of the equipment installed at an isolated village.

\begin{tabular}{ll}
\hline Item Description & Technical Information \\
\hline Wind speed sensor, NRG\#40 & AC sine wave, Accuracy: $0.1 \mathrm{~m} / \mathrm{s}$, Range: $1-96 \mathrm{~m} / \mathrm{s}$ \\
Three cup anemometer & Output: $0-125 \mathrm{HZ}$, Threshold: $0.78 \mathrm{~m} / \mathrm{s}$ \\
Wind direction vane, NRG\#200P & Accuracy: $1 \%$, Range: $360^{\circ} \mathrm{Mechanical}$, Output: 0-Exc. Voltage, \\
Potentiometer & Threshold: $1 \mathrm{~m} / \mathrm{s}$, Dead band: Max $-8^{\circ}$ and Typical $4^{\circ}$ \\
Temperature sensor \#110S & Accuracy: $\pm 1.1^{\circ} \mathrm{C}$, Range: $-40{ }^{\circ} \mathrm{C}$ to $52.5^{\circ} \mathrm{C}$, Output: $0-2.5$ volts \\
Integrated circuit & DC, Operating temperature range: $-40{ }^{\circ} \mathrm{C}$ to $52.5{ }^{\circ} \mathrm{C}$ \\
Barometric pressure sensor BP20 & Accuracy: $\pm 15 \mathrm{mb}$, Range: $150-1150 \mathrm{mb}$, Output: Linear voltage \\
Relative humidity sensor RH-5 & Accuracy: $\pm 5 \%$, Range: $0-95 \%$ \\
Polymer resistor & Output: $0-5$ volts, Operating temperature range: $-40{ }^{\circ} \mathrm{C}$ to $54^{\circ} \mathrm{C}$ \\
Pyranometer Li-Cor \#LI-200SA & Accuracy: $1 \%$, Range: $0-3000 \mathrm{~W} / \mathrm{m}^{2}$, Output: Voltage DC, \\
Global solar radiation & Operating temperature range: $-40^{\circ} \mathrm{C}$ to $65^{\circ} \mathrm{C}$ \\
\hline
\end{tabular}

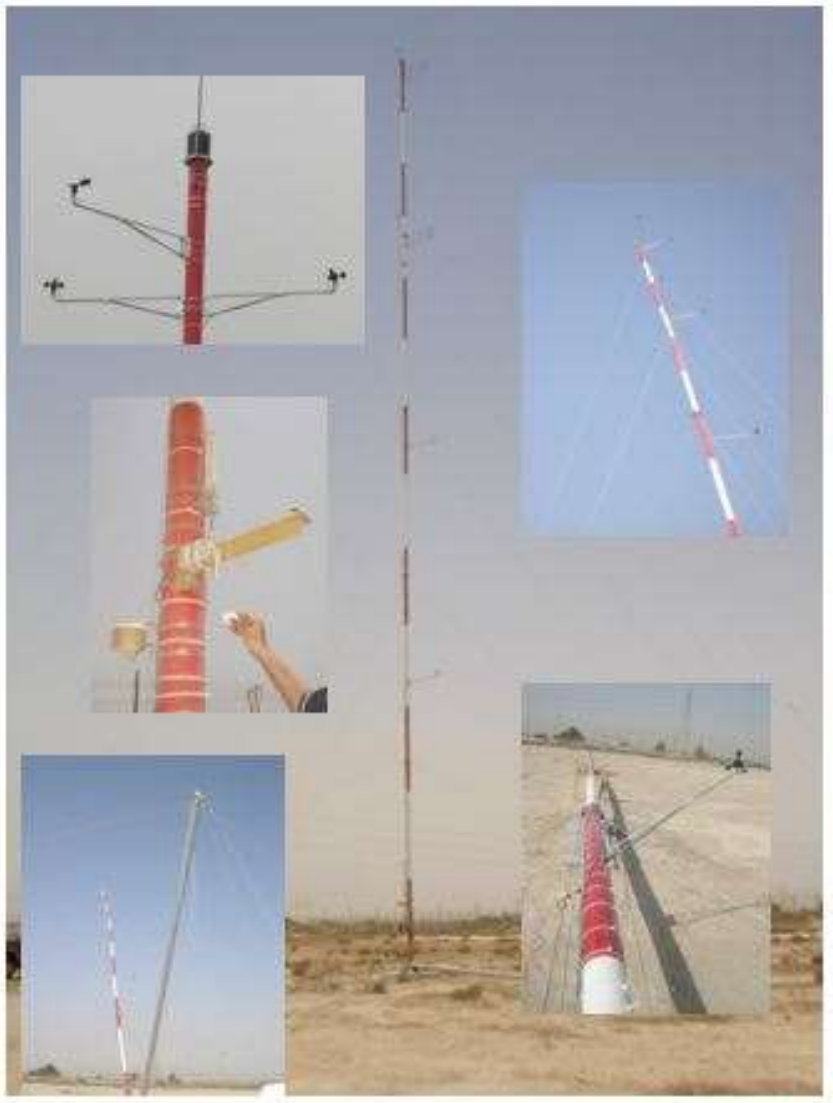

Fig. 2. Wind and meteorological data measurement tower. 
Table 3

Site dependent roughness length, class and description.

\begin{tabular}{lcccc}
\hline \multicolumn{1}{c}{ Location } & WSE & $\begin{array}{c}\text { Roughness } \\
\text { length, m }\end{array}$ & $\begin{array}{c}\text { Roughness } \\
\text { class }\end{array}$ & $\begin{array}{c}\text { Roughness } \\
\text { description }\end{array}$ \\
\hline Rawdat Ben Habbas & 0.302 & 1.81 & 4.41 & Suburban \\
Juaymah & 0.228 & 0.239 & 2.72 & Many trees \\
Arar & 0.181 & 0.138 & 2.27 & Few trees \\
Dhahran & 0.161 & 0.056 & 1.52 & Crops \\
Gassim & 0.249 & 1.070 & 3.97 & Suburban \\
Yanbo & 0.073 & 0 & 0 & Smooth \\
Dhulom & 0.185 & 0.134 & 2.25 & Few trees \\
\hline
\end{tabular}

\section{Hub Height Optimization Correlation}

To establish empirical correlations of optimum hub height $(\mathrm{HH})$ with wind shear exponents, ten minutes average wind speed data from seven stations listed in Table 1 was used. The measured wind speed data at 20,30, and 40m above ground level was first used to estimate the wind shear exponent. These wind shear exponent values (given in Table 3) were sued to estimate wind speed at 50, 60, 70, 80, 90, and 100m AGL. For wind turbines of 2000, 3000 and 4000, and $5000 \mathrm{~kW}$ the wind speeds were extrapolated to 110 and $120 \mathrm{~m}$ as well. As third step, these extrapolated wind speed values were used in conjunction with wind power curves of chosen wind turbines from different manufacturers to estimate the energy output. The wind power curve of the chosen wind turbines are shown in Fig. 3. The technical specifications of the chosen wind turbines are summarized in Table 4. The resulting annual wind energy yields from $1000 \mathrm{~kW}$ rated power (Model AAER A-1000) wind turbine at different heights for all the stations are summarized in Table 5 and are also compared in Fig. 4. It is evident from data given in Table 5 and the Fig. 4, that energy yield increases with increasing hub height.

The corresponding percent increases in annual energy yield with increase in hub height are summarized in Table 6. As seen from Table 6, maximum increase in annual energy is observed while increasing hub height form 40 to $50 \mathrm{~m}$. In order to find out the optimal hub height, the cost of wind turbine including the capital and installation cost was obtained from Morthorst [20] to be 900Euro/kW for a hub height of 40meters. The cost of the wind turbine as a whole and hub height in addition has been estimated by considering various costs such as blades, hub, pitch mechanisms and bearings, spinner, nose cone, drive train, nacelle, low-speed shaft, bearings, gearbox , mechanical brake, high-speed coupling, and associated components, generator, variable-speed electronics, yaw drive and bearing, main frame, electrical connections, hydraulic and cooling systems, nacelle cover, control, safety system, and condition monitoring, tower, 
foundation/support structure, transportation, assembly and installation, electrical interface/connections, and engineering permits.

The increase in hub height of a turbine basically adds the civil construction and installation cost which varies from 6 to $20 \%$ of the total investment cost. Based on initial cost and incremental cost, the total cost of wind turbine with incremental hub height was worked out to be as summarized in Table 7. As next step, the percent increase in energy yield and the total wind turbine cost with increasing hub height for $1000 \mathrm{~kW}$ rated power wind turbine is plotted for each station, as shown in Figs. 5(a) to 5(g) for Arar, Dhahran, Dhulom, Gassim, Juaymah, Rawdat Ben Habbas $(\mathrm{RBH})$ and Yanbo, respectively. The optimal hub height is defined as the height where two curves cross each other. For Arar, as seen from Fig. 5(a), the two curves cross each other at point where the hub height is 68 meters. Similarly the optimal hub heights for Dhahran, Dhulom, Gassim, Juaymah, and Raddat Ben Habbas were found to be 64, 66, 81, 70 and 82 meters, respectively as can be seen from Figs. 5(b) to 5(f). In case of Yanbo [Fig. 5(g)], the two curves did not cross each other due to abnormally small value of wind shear exponent, so the optimal hub height is assumed to be $50 \mathrm{~m}$ in this case.

\section{Table 4}

Technical specifications of the wind turbines used in the present analysis.

\begin{tabular}{lccccc}
\hline \multicolumn{1}{c}{ Wind turbine } & $\begin{array}{c}\text { Rotor } \\
\text { Diameter } \\
(\mathrm{m})\end{array}$ & $\begin{array}{c}\text { Rated } \\
\text { power } \\
(\mathrm{kW})\end{array}$ & $\begin{array}{c}\text { Cut-in- } \\
\text { speed }(\mathrm{ms})\end{array}$ & $\begin{array}{c}\text { Rated } \\
\text { speed } \\
(\mathrm{m} / \mathrm{s})\end{array}$ & $\begin{array}{c}\text { Cut-out- } \\
\text { speed }(\mathrm{m} / \mathrm{s})\end{array}$ \\
\hline Suzlon S.52 & 52 & 600 & 4 & 13 & 25 \\
AAER A-1000 & 58 & 1000 & 3 & 12 & 22 \\
Repower MM92 & 92.5 & 2000 & 3.5 & 11 & 24 \\
Vestas V112 & 112 & 3000 & 2.5 & 11 & 25 \\
Siemens SWT-3.6 & 107 & 3600 & 3 & 14 & 25 \\
Repower 5M & 126 & 5000 & 3.5 & 13 & 25 \\
\hline
\end{tabular}




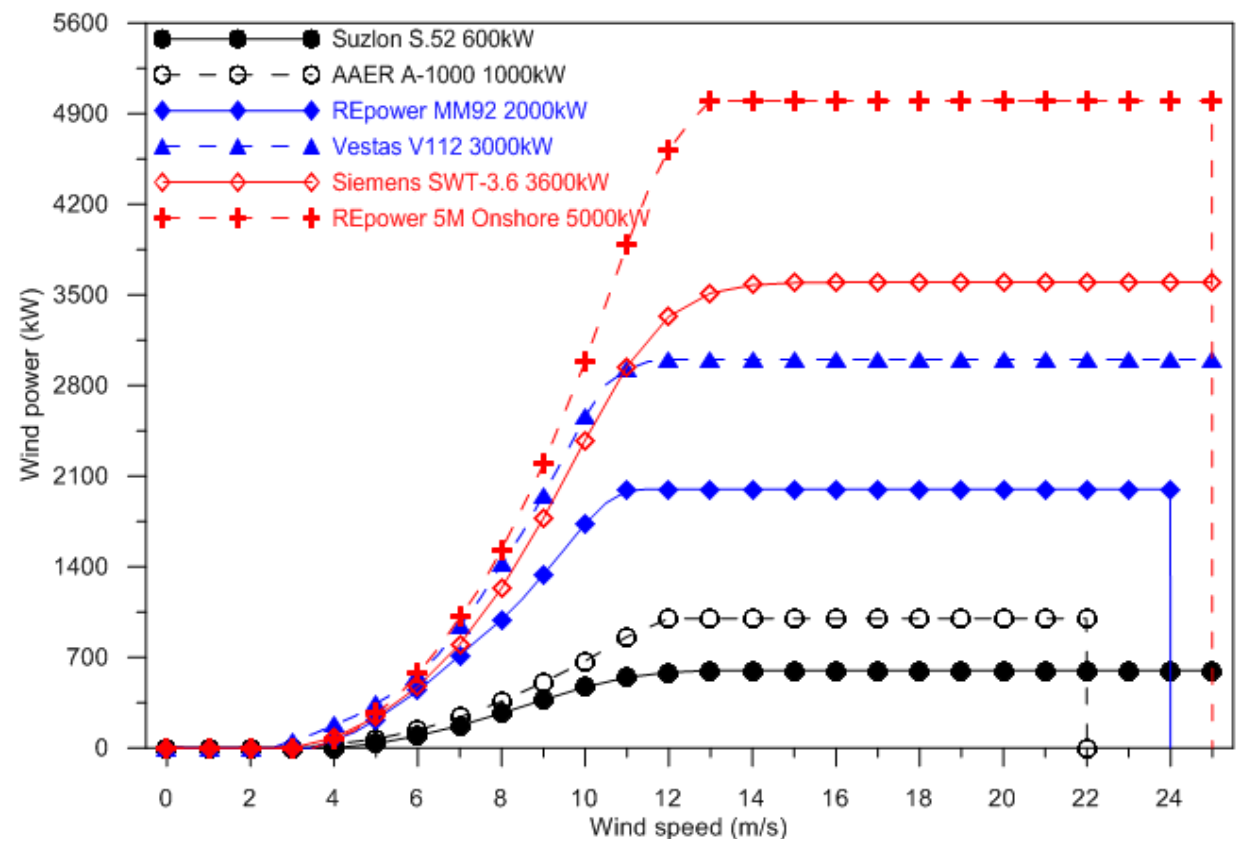

Fig. 3. Wind power curves of wind turbines used for energy estimation.

Table 5

Annual energy yield from $1000 \mathrm{~kW}$ wind turbine at different hub heights.

\begin{tabular}{|c|c|c|c|c|c|c|c|}
\hline \multirow{2}{*}{ HH } & \multicolumn{7}{|c|}{ Annual energy yield (MWh) } \\
\cline { 2 - 8 } & Arar & Dhahran & Dhulom & Gassim & Juaymah & Rawdat & Yanbo \\
\hline 40 & 1225.4 & 1137.9 & 1162.5 & 635.2 & 1338.0 & 1256.8 & 988.4 \\
\hline 50 & 1353.3 & 1252.9 & 1451.9 & 758.6 & 1530.3 & 1533.7 & 1029.6 \\
\hline 60 & 1467.4 & 1355.4 & 1585.2 & 880.4 & 1703.1 & 1774.9 & 1067.9 \\
\hline 70 & 1594.9 & 1446.3 & 1703.5 & 996.0 & 1858.4 & 2008.9 & 1101.0 \\
\hline 80 & 1700.1 & 1528.0 & 1810.1 & 1109.1 & 2008.8 & 2251.2 & 1130.2 \\
\hline 90 & 1796.5 & 1602.5 & 1907.0 & 1206.1 & 2125.9 & 2409.8 & 1156.3 \\
\hline 100 & 1884.9 & 1670.7 & 1995.8 & 1324.9 & 2243.4 & 2664.5 & 1180.0 \\
\hline
\end{tabular}

The energy yield and respective percent increase with incremental change in hub height was calculated for wind turbines of rated power 600, 2000, 3000, 3600, and 5000kW and data similar to what presented in Tables 5 and 6 and Fig. 4 was obtained. To find out the optimal height, the percent increase in energy yield and the cost were plotted for above wind turbines similar to Fig. 5 , but are not shown here to contain the length of the paper. 


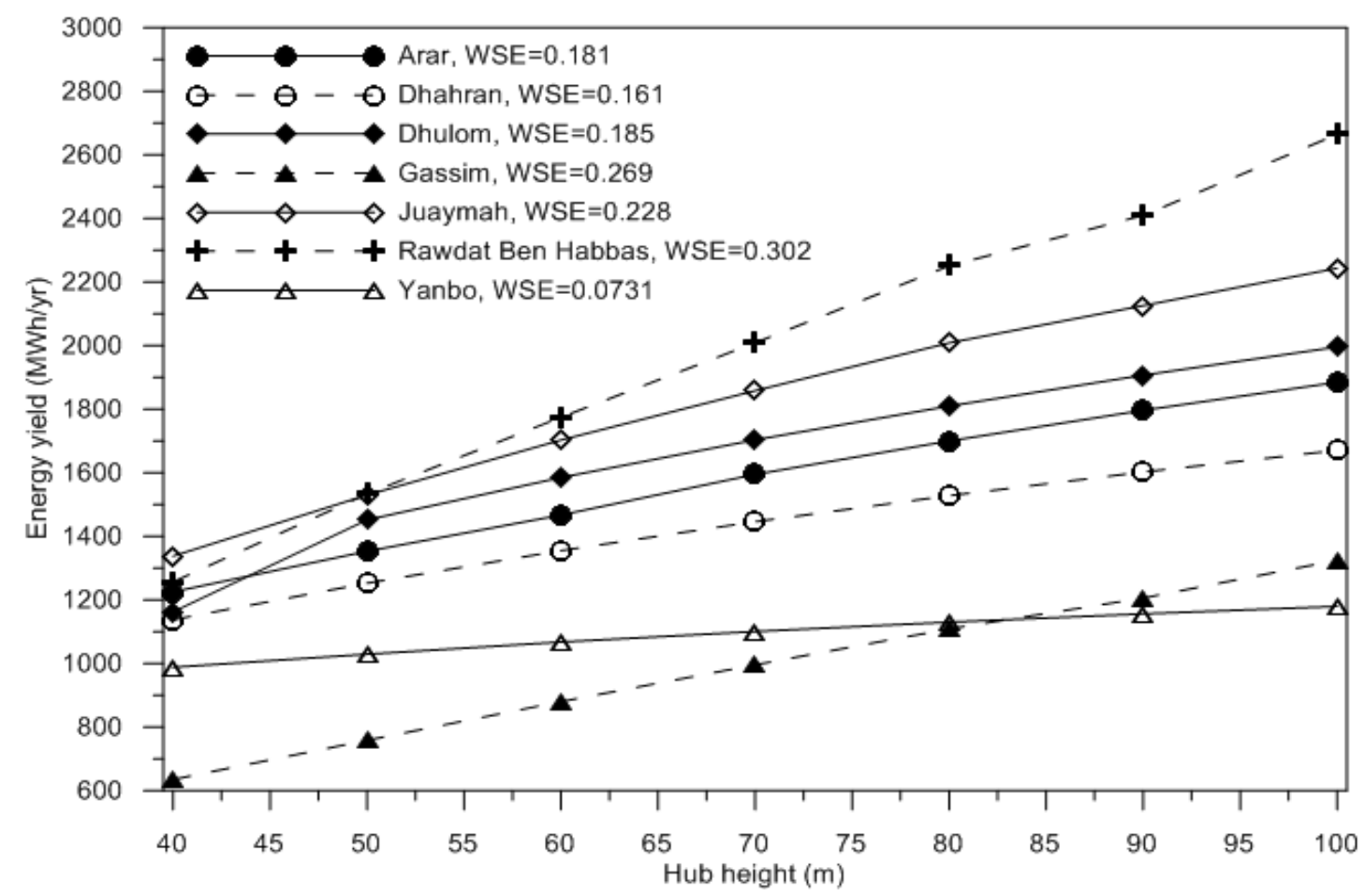

Fig. 4. Comparison of annual energy yields from $1000 \mathrm{~kW}$ wind turbine at different hub heights with wind shear exponents.

Table 6

Percent increase in annual energy yield with increase in hub height for $1000 \mathrm{~kW}$ wind turbine.

\begin{tabular}{|r|r|r|r|c|c|c|c|}
\hline \multirow{2}{*}{ HH } & \multicolumn{6}{|c|}{ Percent increase in annual energy yield with change in hub height } \\
\cline { 2 - 8 } & Arar & Dhahran & Dhulom & Gassim & Juaymah & Rawdat & Yanbo \\
\hline 40 & - & - & - & - & - & - & - \\
\hline 50 & 10.4 & 10.1 & 24.9 & 19.4 & 14.4 & 22.0 & 4.2 \\
\hline 60 & 8.4 & 8.2 & 9.2 & 16.1 & 11.3 & 15.7 & 3.7 \\
\hline 70 & 8.7 & 6.7 & 7.5 & 13.1 & 9.1 & 13.2 & 3.1 \\
\hline 80 & 6.6 & 5.7 & 6.3 & 11.3 & 8.1 & 12.1 & 2.6 \\
\hline 90 & 5.7 & 4.9 & 5.4 & 8.7 & 5.8 & 7.0 & 2.3 \\
\hline 100 & 4.9 & 4.3 & 4.7 & 9.8 & 5.5 & 10.6 & 2.0 \\
\hline
\end{tabular}

Table 7

Total incremental cost of $1000 \mathrm{~kW}$ wind turbine.

\begin{tabular}{|c|c|c|}
\hline HH & $\begin{array}{l}\text { Total capaital and installation cost of 1000kW } \\
\text { wind turbine (Euro) }\end{array}$ & $\begin{array}{l}\text { Percent increase in } \\
\text { total cost }\end{array}$ \\
\hline 40 & 900,000 & - \\
\hline 50 & 954,000 & 6 \\
\hline 60 & $1,020,780$ & 7 \\
\hline 70 & $1,112,650$ & 9 \\
\hline 80 & $1,235,000$ & 11 \\
\hline 90 & $1,395,600$ & 13 \\
\hline 100 & $1,618,900$ & 16 \\
\hline
\end{tabular}



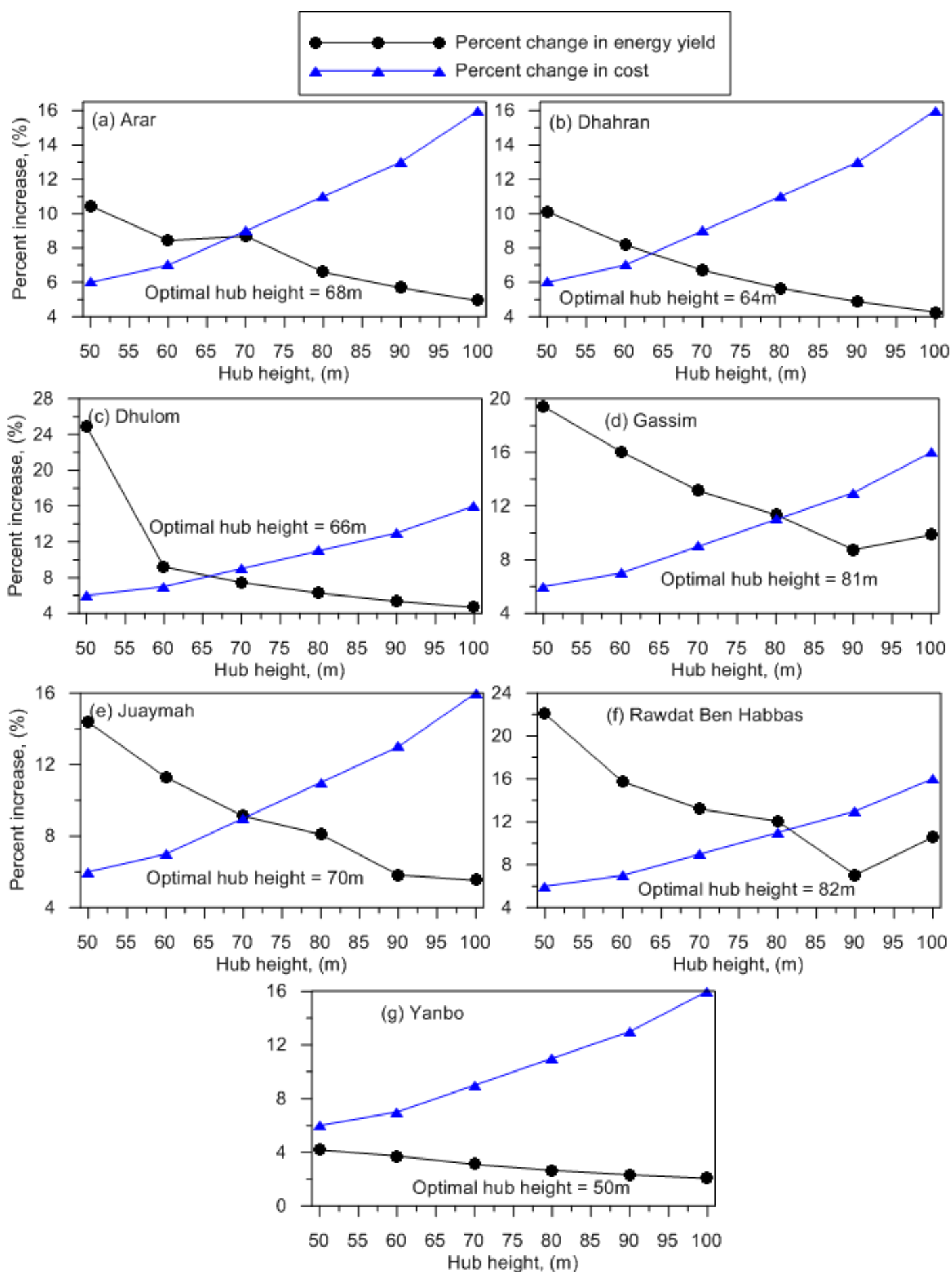

Fig. 5. Percentage increase in energy yield from $1000 \mathrm{~kW}$ wind turbine and the total cost of installation with increasing hub height.

Finally, in order to find an empirical relation between optimal hub height and the wind shear exponent $(\alpha)$, the two are plotted in Fig. 6(a) and best fit curves were obtained for 600kW wind turbine. Three types of best fit curves obtained for $600 \mathrm{~kW}$ wind turbine are viz. Linear fit 
(Equation 1), Log fit (Equation 2), and Power fit (equation 3). The values of the coefficient of determination for the three best fit curves were found to be $0.97,0.94$, and 0.97 , respectively. The linear and power fit equations were found to be the best approximation of optimal hub height with wind shear exponent given by equation 1 and 3. Similar types of correlations were obtained for $1000 \mathrm{~kW}, 2000 \mathrm{~kW}, 3600 \mathrm{~kW}$, and 5000kW wind turbines as shown in Figs. 6(b), 6(c), 6(d), 6(e), and 6(f); respectively. The resulting empirical equations (linear, log and power fit) along with square of coefficient of determinations are summarized in Table 8. As observed form the data in Table 8, the best correlation was obtained for wind turbine of $1000 \mathrm{~kW}$ rated with $\mathrm{R}^{2}$ value always more than $95 \%$. Among three approached used for obtaining the empirical correlations, power law yielded in the best results whereas $\mathrm{R}^{2}$ values was concerned.

\section{Linear fit equation:}

$\mathrm{HH}=142.035 *(\alpha)+40.33$

Residual sum of squares $=20.30$

Residual mean square, sigma-hat-sq'd $=4.06$

\section{Log fit equation:}

$\mathrm{HH}=22.533 * \ln (\alpha)+106.79$

Residual sum of squares $=46.357$

Residual mean square, sigma-hat-sq'd $=9.27$

\section{Power fit equation:}

$\ln (\mathrm{HH})=0.35 * \ln (\alpha)+4.81$

Alternate $(\mathrm{HH})=[(\alpha) * * 0.3501] * 122.7449$

Residual sum of squares $=0.0055$

Residual mean square, sigma-hat-sq'd $=0.0011$
(1)

Coeff. of determination, R-squared $=0.97$

\section{Table 8}

Hub height estimation empirical correlations for different ranges of rated power of wind turbines.

\begin{tabular}{|c|c|c|c|c|c|c|}
\hline $\begin{array}{l}\text { Rated } \\
\text { Power }\end{array}$ & \multicolumn{3}{|c|}{ Empirical correlation } & \multicolumn{3}{|c|}{$\begin{array}{l}\text { Correlation coefficient } \\
\qquad\left(\mathrm{R}^{2}\right)\end{array}$} \\
\hline$(\mathrm{kW})$ & Linear & Log & Power & Linear & Log & Power \\
\hline 600 & $154.49 * x+41.55$ & $25.33 * \ln (x)+115.22$ & $0.342 * \ln (\mathrm{x})+4.916$ & 0.81 & 0.83 & 0.86 \\
\hline 1000 & $142.03 * x+40.33$ & $22.53 * \ln (x)+106.79$ & $0.331 * \ln (\mathrm{x})+4.810$ & 0.97 & 0.94 & 0.97 \\
\hline 2000 & $127.12 * x+55.16$ & $21.57 * \ln (x)+117.03$ & $0.297 * \ln (\mathrm{x})+4.872$ & 0.75 & 0.82 & 0.84 \\
\hline 3000 & $129.95 * x+55.17$ & $22.09 * \ln (x)+118.48$ & $0.291 * \ln (\mathrm{x})+4.889$ & 0.76 & 0.84 & 0.86 \\
\hline 3600 & $145.75^{*} x+56.08$ & $25.26 * \ln (x)+127.89$ & $0.350 * \ln (\mathrm{x})+4.994$ & 0.80 & 0.92 & 0.91 \\
\hline 5000 & $150.58 * x+56.45$ & $26.27 * \ln (x)+130.93$ & $0.384 * \ln (\mathrm{x})+5.027$ & 0.78 & 0.91 & 0.91 \\
\hline
\end{tabular}



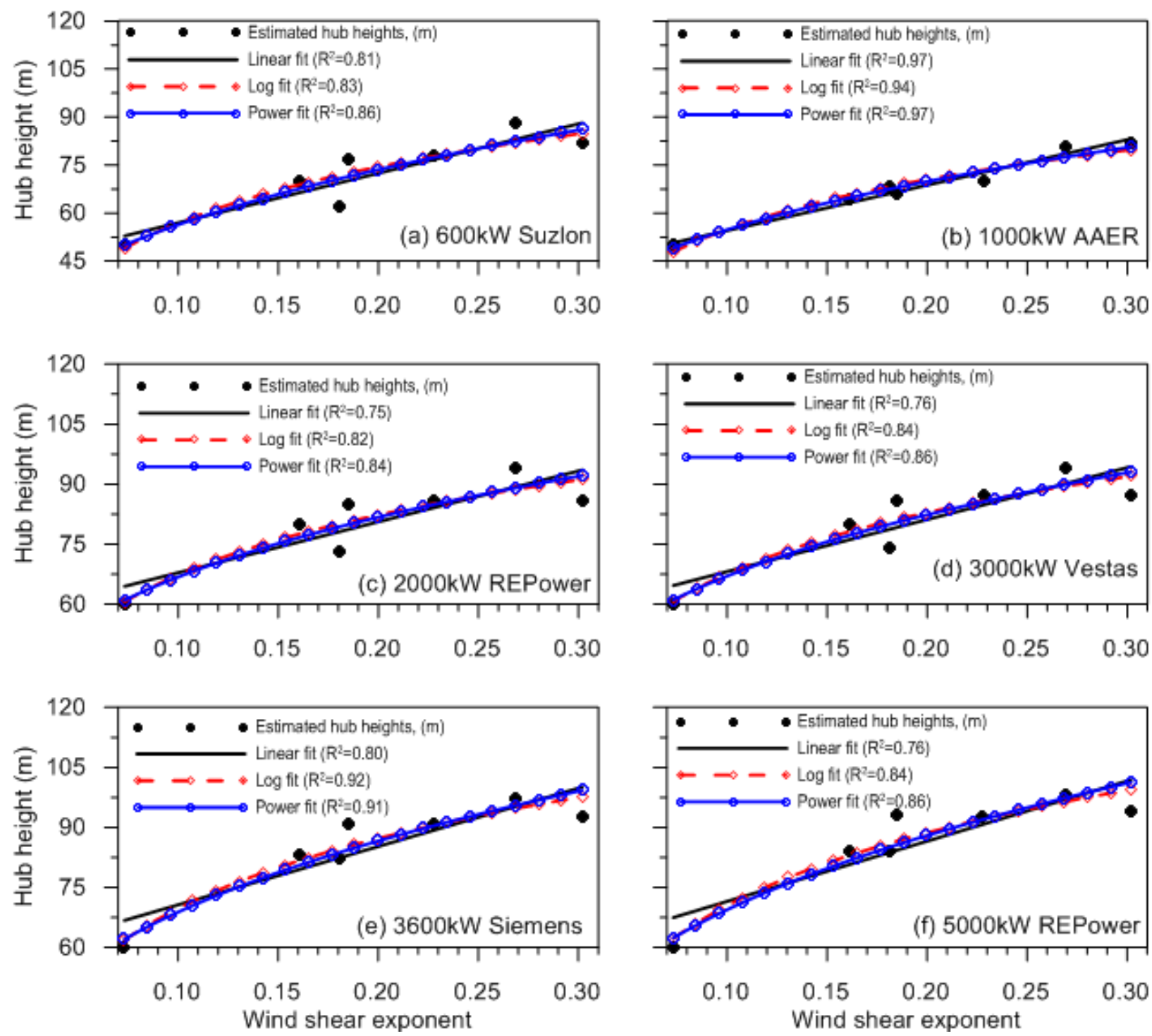

Fig. 6. Optimal hub height variation with wind shear exponent.

\section{Conclusions}

In the present study, as attempt has been made to correlate the optimal hub height with the local wind shear exponent which is a critical parameter used to extrapolate the wind speed to hub heights of the wind turbines which is usually much more than the actual height of wind measurements. For the purpose, wind speed measurements at 20,30, and 40 meters above ground level were used to obtain the local wind shear exponents at Arar, Dhahran, Dhulom, Gassim, Juaymah, Rawdat Ben Habbas and Yanbo. These wind shear exponents were used to extrapolate the wind speed to different hub heights which in turn were used to get the energy yield from different chosen wind turbines of rated power 600, 1000, 2000, 3000,36000, and 
$5000 \mathrm{~kW}$. Next, the incremental percent energy yield and the corresponding incremental percent costs were plotted to get the optimal or near optimal hub heights. Finally, these hub heights were used in conjunction with the local wind shear exponents to obtain the correlations between the local wind shear exponents and the hub height. Bets correlations were obtained for wind turbine of $1000 \mathrm{~kW}$ with $\mathrm{R}^{2}$ value always more than $95 \%$. The Power law fit produced relatively better empirical correlations between the optimal hub height and the local wind shear exponents with higher values of coefficient of determination. These correlations can be used to obtain an optimal hub height to produce energy at the site of interest with maximum energy output at an optimal cost.

As future work of scope, this methodology should be used for as many sites as possible and other wind turbines to obtain the empirical correlations for more realistic output.

\section{Acknowledgements}

The author wishes to acknowledge the support of the Research Institute of King Fahd University of Petroleum and Minerals, Dhahran, Saudi Arabia.

\section{Reference}

[1] Rural Energy and Development for Two Billion People, Meeting the Challenge for Rural Energy and Development, The World Bank, Vice Presidency for Finance and Private Sector Development, Industry \& Energy Department, , 1818 H Street NW, Washington DC 20433, USA. http://siteresources.worldbank.org/INTENERGY/Resources/Rural_Energy_Development Paper_Improving_Energy_Supplies.pdf (Accessed on November 29, 2012)

[2] Ucar A, Balo F. Investigation of wind characteristics and assessment of wind generation potentiality in Uludag-Bursa, Turkey. Appl Energy 2009;86(3):333-339.

[3] Bekele G, Palm B. Wind energy potential assessment at four typical locations in Ethiopia. Appl Energy 2009;86:388-96.

[4] Fyrippis I, Axaopoulos PJ, Panayiotou G. Wind energy potential assessment in Naxos Island, Greece. Appl Energy 2010;87:577-86.

[5] Global Wind Energy Council (GWEC), 2011. Global wind power boom continues despite economic woes http://www.gwec.net/index.php?id=30\&no_cache=1\&tx_ttnews[tt_news]=247\&tx_ttnews[ backPid $=4 \& \mathrm{cHash}=1196 \mathrm{e} 940 \mathrm{a} 0$ (Accessed on February 12 2012)

[6] Mohandes M, Rehman S, Rahman SM. Estimation of wind speed profile using adaptive neuro-fuzzy inference system (ANFIS). Appl Energy 2011;88:4024-4032.

[7] The Encyclopedia of Alternative Energy and Sustainable Living http://www.daviddarling.info/encyclopedia/H/AE hub_height.html (accessed on May 6 2012) 
[8] Hoffmann AR, Fallen M, Wolfanger T, Ebert F. Hub height and profitability of WECs in complex terrain, European wind Energy Conference, 1-5 March 1999, Nice, France, pp. 542-544.

[9] Pat Fox, Wind Turbines: Three Critical Factors for a Successful Site, http://patfox.hubpages.com/hub/Wind-Turbines--Three-Critical-Factors-for-a-SuccessfulSite (accessed on May 6, 2012)

[10] Can the wind speed be increased at a site? http://www.renewablesfirst.co.uk/introductionto-farm-wind-and-medium-wind-turbines.html\#link4 (accessed on May 6, 2012)

[11] Firtin E, Guler O, Akdag SA. Investigation of wind shear coefficients and their effect on electrical energy generation. Appl Energy 2011;88:4097-4105.

[12] Yoshida S. Wind Turbine Tower optimization method using a genetic algorithm. Wind Engineering 2006;30(6):453-470.

[13] Rehman S, Al-Abbadi NM. Wind power characteristics on the north west coast of Saudi Arabia. Energy \& Environment 2010;20(8)/21(1):1257-1270.

[14] Al-Abbadi NM, Rehman S. Wind speed and wind power characteristics for Gassim, Saudi Arabia. International Journal of Green Energy 2009;6(2):210-217.

[15] Rehman S, Al-Abbadi NM. Wind shear coefficient, turbulence intensity and wind power potential assessment for Dhulom, Saudi Arabia. Renewable Energy 2008;33:2653-2660.

[16] Rehman S, Al-Abbadi NM. Wind shear coefficients and energy yield for Dhahran. Renewable Energy 2007;32(5):738-749.

[17] Rehman S, Al-Abbadi NM. Wind shear coefficients and their effect on energy production. Energy Conversion and Management 2005;46(15-16):2578-2591.

[18] Mahbub AM, Rehman S, Meyer J, Al-Hadhrami LM. Review of 600kw to 2500kw sized wind turbines and optimization of hub height for maximum wind energy yield realization. Renewable and Sustainable Energy Reviews 2011;15(1):3839-3849.

[19] Rehman S, Ahmad A, El-Amin I, Al-Hadhrami LM. Assessment of wind power, wind exponent, local air density and air turbulence intensity for an isolated site. International Journal of Sustainable Energy. 2009;28(4):217-230.

[20] Morthorst P E. Costs and prices: wind energy - the facts, Volume 2, http://www.ewea.org/fileadmin/ewea_documents/documents/publications/WETF/Facts_Vo lume_2.pdf (Accessed 22 August 2011) 